\title{
IMIGRAÇÃO BRASILEIRA \\ CONTEMPORÂNEA: BRASILEIRAS E \\ BRASILEIROS NA ESPANHA
}

Taís Cristina Samora de Figueiredo ${ }^{1}$

Resumo: Este artigo apresenta resultados parciais de pesquisa de doutoramento, em que se busca apresentar a diáspora brasileira, realizando um recorte geográfico e detalhando esta imigração na Espanha. Através de uma revisão bibliográfica e, também, com base em dados de investigação é exposto o que representa o coletivo brasileiro no país, sobretudo na Catalunha. Caracterizada por ser uma nacionalidade invisibilizada no contexto imigratório, com exceção de Portugal, dados recentes são apresentados sobre as brasileiras e brasileiros neste contexto, destacando-se ainda o que representa a imigração feminina em tal cenário de invisibilidade. Em Barcelona, embora o coletivo brasileiro se apresente numericamente pequeno, em comparação com outras nacionalidades, se encontra bem representado, já que muitos deles vivem ali com nacionalidade europeia e parecem expressar "en las calles" sua brasilidade.

Palavras-chave: Imigração Brasileira. Espanha. Barcelona. Gênero. Língua de Herança.

Abstract: This article presents partial results of doctoral research, in which the Brazilian diaspora is presented, making a geographic cut and detailing this immigration in Spain. It is presented through a bibliographical review and, also, from research data that represents the Brazilian collective in the country, and specifically in Catalonia. Characterized by being a nationality invisibilized in the context of immigration, with

${ }^{1}$ Doutoranda em Antropoligia Social e Cultural na Universidade Autônoma de Barcelona (UAB), Espanha, sob orientação da professora doutora Beatriz Ballestín Gonzales; Mestre em Antropolia pela Universidade Federal de Sergipe (UFS); Graduada em Letras na Universidade do Oeste de Santa Catarina (UNOESC); faz parte do Grupo de Pesquisa de Estudos e Pesquisa "Processos Identitários e Poder" - GEPPIP/UFS, sob coordernação do professor doutor Marcelo Alario Ennes. E-mail: tais_samora@ hotmail.com. 
the exception of Portugal, recent data on Brazilian immigrants in this context, it is highlighted what represents the female immigration in such an invisibility scenario. In Barcelona, although the Brazilian collective appears numerically small compared to other nationalities, it is very representative, since many of them live there with a European nationality and seem to express "in the streets" their Brazilianness.

Keywords: Brazilian Immigration. Spain. Barcelona. Gender. Heritage Language.

\section{Introdução}

Este artigo é parte do resultado de uma investigação de doutoramento em Antropologia que está em andamento na Universidade Autônoma de Barcelona, em que é investigado quem são os imigrantes brasileiros(as) que estão envolvidos na formação de iniciativas (associações, escolas, eventos, encontros) que promovem o ensino da língua e cultura brasileira no exterior, chamada por suas agentes de Português como Língua de Herança (PLH) ${ }^{2}$, para filhos de brasileiras (os) nascidos no exterior ou não.

O estudo sobre a migração internacional brasileira tornou-se de extrema relevância para a pesquisa, já que são tratadas de iniciativas formadas por brasileiras (os) que se mobilizam fora do Brasil para manter e/ou ensinar sua língua e sua cultura para seus filhos e filhos de outras brasileiras e brasileiros no exterior, visando despertar nessas crianças o ${ }^{2}$ Jose Carlos Paes de Almeida Filho (UnBBrasil) destaca que O Português como Língua de Herança (PLH) é uma especialidade do Português como Língua Estrangeira (PLE) e se caracteriza em um contexto em que o Português e a cultura (brasileira neste caso) são ensinados a filhos de brasileiros imigrados no exterior. O termo "herança" se refere ao desejo de preservação ou recuperação da língua e cultura nacionais do Brasil como capitais herdados de pais nativos ou quando, por ao menos, um deles é brasileiro (a) que reside com a família em outro país. Disponível em: http://www.sala. org.br/index.php?option $=$ com_content $\&$ view $=$ article $\&$ id $=270$ :portugues-lingua-deheranca\&catid=1116:outras-salas. Acessado em: 15/01/2015 
sentimento de pertencimento de também serem brasileiros. A investigação busca entender como acontece e como surge o interesse dessas pessoas, e apreender o que está em jogo nesse novo formato de mobilização que envolve o ensino da língua e cultura do Brasil, caracterizado por uma imigração transnacional, em que a "ideia de fluidez de um lado para o ouro, através das fronteiras, de pessoas, símbolos, ideias e objetos" (MARGOLIS 2013, p. 242, 2008, p. 296) estão presentes na manutenção das relações com o país de origem.

Inicialmente será apresentado como a imigração brasileira está distribuída pelo mundo, contextualizando o início desse movimento migratório, seus interesses e motivações. Será abordada a imigração brasileira na Espanha, indicando onde se concentram os coletivos desta nacionalidade; ressaltando o coletivo brasileiro que se encontra na Catalunha, sobretudo em Barcelona. Justifico o interesse no coletivo localizado em Barcelona por ser o local onde foi realizada a pesquisa de campo, junto a Associação de Pais de Brasileirinhos da Catalunha. Para finalizar, será apresentado informações sobre as ações do governo brasileiro relativos aos brasileiros na diáspora.

1. Motivações e projetos de vida: das velhas as novas experiências migratórias brasileiras

Os estudos sobre migração internacional têm apontado os anos 80 como o inicio da emigração internacional brasileira e que esta seria uma nova realidade do Brasil (SALES, 1991; MARGOLIS, 2013), pois, até então, o país era caracterizado como receptor de coletivos estrangeiros. A imigração internacional no Brasil é marcada pela chegada dos portugueses nos anos de 1500, e cresceu ao longo dos séculos, especialmente nos séculos XIX e XX, com a vinda de europeu de vários países, como 
também de asiáticos; em comparação a este movimento migratório, a emigração internacional brasileira é descrita como recente.

Segundo Margolis (2013) e Sales (1999), o primeiro movimento de brasileiros para o exterior foi causada pela crise econômica que o país enfrentava a época, caracterizada pela "hiperinflação, desemprego e baixos salários", incentivando os brasileiros a deixarem o país e irem em busca de oportunidades, tendo como destino principal os Estados Unidos. Margolis (2013) destaca que a classe média foi a mais afetada, perdendo seu poder de compra, e o estrangeiro foi visto por eles como uma alternativa para manter seus recursos e capital social, como a educação superior e outros fatores ameaçados pela crise econômica enfrentada. Vale destacar que desde o ano de 2014, o Brasil vem passando novamente por um novo movimento de saída de brasileiros do país, as principais justificativas são novamente: crise econômica, política e a ascensão da violência.

Segundo algumas reportagens de jornais brasileiros ${ }^{3}$, entre os anos de 2014 e 2016, a Receita Federal do Brasil ${ }^{4}$ entregou 55.403 declarações de saída definitiva do país, indicando que em relação ao último triênio anterior, houve um aumento de $81,61 \%$. Outro destaque é dado referente ao aumento de brasileiros em Portugal, onde em 2017 constatou-se 5,1\% de aumento desses imigrantes no país, sendo a maior comunidade de estrangeiros no local. Outro ponto ressaltado nos jornais é o aumento de $59 \%$, de "visto gold", que é concedido para pessoas estrangeiras que investem no país.

Os primeiros estudos sobre a emigração brasileira marcam a

3 Disponivel em: https://economia.estadao.com.br/noticias/geral,com-a-crise-crescenumero-de-brasileiros-que-deixam-o-pais, 70001849689 Acessado em 11/09/2018 https://www1.folha.uol.com.br/mundo/2018/06/numero-de-brasileiros-em-portugalvolta-a-subir-depois-de-seis-anos.shtml Acessado em en 11/09/2018

${ }^{4}$ A Receita Federal é um órgão do Ministério da Fazenda, que tem como responsabilidade a administração dos tributos federais e controle aduaneiro, além de atuar no combate elisão e evasão fiscal, contrabando, pirataria e tráfico de drogas e animais. Para mais informações: http://idg.receita.fazenda.gov.br/sobre/institucional 
década dos anos 90; depois disso, a bibliografia referente ao assunto cresceu de forma considerável ao longo dos anos. Segundo Fusco (2007), as principais preocupações teóricas e empíricas abordavam fatores e elementos que motivavam e atraíam os imigrantes, assim como suas características e as redes sociais formadas no processo migratório. Machado (2015), com base em uma revisão bibliográfica sobre o tema, destaca os principais dilemas enfrentados pelos brasileiros no exterior, ressaltando três categorias centrais nas produções: Trabalho e legalidade; Discriminação social e Reformulações de gênero. Quando as reformulações de gênero, o autor aponta a "mudança de papeis entre homens e mulheres, a independência feminina, as separações e o casamento com estrangeiros." (MACHADO, 2015, p.215).

Considerando a diversidade cultural, histórica, política e econômica dos países receptores de coletivos imigrantes, bem como as trajetórias e histórias individuais, é necessário refletir e considerar que as experiências de brasileiras e brasileiros nos mais diferentes países não se dão de forma uniforme. As trajetórias migratórias são experiências únicas e singulares e o resultado dessas experiências dependerá de cada contexto. As vivências na imigração despertam sensações, conhecimentos e sentimentos que possibilitam desenvolver múltiplos interesses e/ou desinteresses de tal realidade, e há brasileiras, no caso desta investigação, que relatam suas decepções com o que foi vivido, apresentando suas motivações de saída do Brasil e formatos diferentes; por exemplo, uma brasileira do sul do Brasil, casada, com duas filhas, relatou que saiu do Brasil com a família para "tentar uma vida melhor", mesmo tendo no Brasil uma vida "confortável". A violência crescente no país foi a motivação maior para tal movimento, além da decepção com o contexto politico e social que passava o país. Acreditando que com passaporte europeu na mão a adaptação e a inserção profissional do 
marido, por exemplo, fluente em inglês e com grande experiência na área de gestão, fosse mais fácil, porém não imaginavam que a língua, idioma local, o alemão, poderia ser um limitador para a sua adaptação, como também de ascensão profissional, consequentemente, como resultado desta experiência, o desejo de retorno para seu país de origem surgiu muito antes do que imaginam.

Outra experiência relatada é de outra brasileira do Sul do Brasil, que viajou sozinha para realizar um pós-doutorado em Portugal; conta que foi muito difícil se adaptar, pois, segundo ela, os portugueses são "diferentes dos brasileiros, em Porto as pessoas são tristes, briguentos, antipáticos...e nós brasileiros sempre alegres, damos risadas de tudo... eles estranham. Acredito que Lisboa es mais legal, e mais cosmopolita". Neste caso, a brasileira passou seis meses em Portugal, ao final de seus estudos retornou para o Brasil, para sua casa e seu trabalho. Uma história diferente, com motivação, tempo e propósitos diferentes do caso anterior, em que o projeto migratório é familiar, sem data de retorno prevista, e o retorno ao Brasil implica ter condições de realizar esta volta, como, por exemplo, ter emprego.

Em contra-partida, foram ouvidos outros relatos em que o retorno para o Brasil não faz parte dos projetos de vida dessas brasileiras. Brasileiras que dizem ter se adaptado muito bem na cidade escolhida para viver, e que visitar o país de origem "às vezes" (uma vez ao ano, ou ainda a cada dois, três anos) é o suficiente para "matar a saudade". Outras experiências migratórias são relatadas de forma tão bem-sucedida que permitem com que a família (mãe, irmãos) que ficou no Brasil migre para onde estão.

Os casos apresentados servem para ilustrar a importância de se refletir sobre as trajetórias migratórias, considerando cada experiência como única e individual, pois cada pessoa carrega em sua mala seus 
sonhos, seus projetos e suas histórias, que se apresentam de formas distintas, assim como suas motivações também o são e o resultado dessas experiências individuais, ou familiares, dependerá de cada realidade vivida. Mesmo tendo uma gama de informações sobre o lugar escolhido para emigrar, a facilidade de comunicação com os familiares que ficaram no Brasil e a possibilidade de viver a experiência desejada, como, por exemplo, a busca por "qualidade de vida", essas brasileiras enfrentam muitos desafios que não estavam previstos, ou imaginados, na vivência do sonho de uma "nova vida" no estrangeiro.

\section{Imigracão brasileira na Europa: em busca de "qualidade de vida"}

O relato apresentado anteriormente corrobora o que apontam Machado (2015), Margolis (2013, 2008) e Sales (1999) sobre os estudos de emigração internacional brasileira, que destacam que desde os primeiros movimentos migratórios até hoje, os imigrantes brasileiros saem de seu país em busca de melhores oportunidades, tanto de trabalho como qualidade de vida, como também para conseguir guardar dinheiro para projetos futuros no Brasil. Embora as práticas transnacionais ${ }^{5}$ tenham estado presentes em menor ou maior medida, a depender da época, nos movimentos migratórios como sugerem Solé, Cavalcanti e Parella (2008), é fato que as novas tecnologias da informação possibilitaram

${ }^{5}$ Segundo Glick Schiller, Bach y Szanton Blanc, (1992: 1-2, apud Solé, Parella y Cavalcanti, 2008, p. 15) "transnacionalismos são os processos através dos quais os imigrantes constroem campos sociais que conectam seu país de origem e seu país de assentamento. Os imigrantes que constroem campos sociais são designados «transmigrantes». Os transmigrantes desenvolvem e mantêm múltiplas relações familiares, econômicas, sociais, organizacionais, religiosas, políticas - que sobre passam fronteiras. Os transmigrantes atuam, tomam decisões e se sentem implicados, e desenvolvem identidades dentro das redes sociais que os conectam a eles com dois ou mais sociedades de forma simultânea" (Tradução da autora). 
novas dinâmicas e relações no espaço de imigração, seja para obter informações sobre os destinos almejados, seja como facilitador para adaptação e reconstrução das vidas imigrantes.

Segundo os dados do Ministério das Relações Exteriores do Brasil (MRE), há mais de três milhões de brasileiras e brasileiros imigrados ${ }^{6}$ em diferentes países, estando na América do Norte a maior concentração deles. Desde o inicio do movimento emigratório de brasileiros, até hoje, os Estados Unidos foi o principal destino (ASSIS, 1995; SALES, 1999; MARGOLIS, 2013). Segundo Margolis, a partir do início dos anos 1940, Os Estados Unidos tomaram conta do "imaginário geográfico" dos brasileiros que admiravam os filmes, a música e a tecnologia norte-americanos, ao mesmo tempo que viam o modo de vida daquela sociedade através de lentes cor-de-rosa. Ao saturar o público brasileiro com representações do que seria una vida boa, no estilo norte americano, a mídia brasileira desempenhou um papel no fluxo migratório, ainda que de maneira não intencional (MARGOLIS, 2013, p.33).

Com base nos dados disponibilizados pelo MRE, o maior coletivo de brasileiros no estrangeiro está nos Estados Unidos da América são mais de um milhão e quatrocentos mil brasileiros no país, representando um terço de todos os brasileiros emigrados. O segundo destino escolhido pelos brasileiros é a Europa, são 750.983 no continente, representando $24 \%$ da população emigrada. Na Europa encontramos os maiores coletivos no Reino Unido (120.000), Portugal (116.271), Espanha (86.691), Alemanha (85.272) e Suíça (81.000), e estão presentes em 35 países, segundo os últimos dados do MRE.

${ }^{6}$ Dados das estimativas populacionais realizadas pelo MRE atualizados em 26/11/2016. Disponível em: http://www.brasileirosnomundo.itamaraty.gov.br/a-comunidade/ estimativas-populacionais-das-comunidades/Estimativas\%20RCN\%202015\%20-\%20 Atualizado.pdf 
O Ministério das Relações Exteriores do Brasil esclarece que os números referentes à diáspora brasileira são uma estimativa, em que foram levados em conta muitos fatores, como: "dados oficiais dos países receptores; censos oficiais; números de eleitores registrados nas jurisdições correspondentes, número de matriculados nos consulados, questionários realizados junto às comunidades, solicitações de passaporte, dados disponíveis de saída e retorno de brasileiros", e ainda foi conjugada a esses fatores a pergunta específica do Censo sobre o número de familiares residentes em outros países. Segundo a MRE, é preciso considerar que vários brasileiros se encontram em situação migratória irregular e isso resulta na não participação nos questionários e censos, e ainda se incluem os que não realizam sua matrícula em repartições consulares, dificultando obter dados mais precisos ${ }^{7}$.

Vale destacar que há alguns facilitadores que fazem com que as brasileiras e brasileiros migrarem para a Europa como, por exemplo: não necessitarem visto para turista no espaço $S_{c h e n g e n}{ }^{8}$ pelo período de noventa dias, como também muito brasileiros terem dupla cidadania (por exemplo: espanhola, italiana, portuguesa), devido à imigração europeia para o Brasil Brasil. Além desses "facilitadores", Margolis (2013) aponta que há outros fatores que estimulam os brasileiros a migrarem para a Europa, como: a dificuldade de conseguir visto de turismo para viajar para os E.U.A depois dos ataques de 11 de setembro, junto com o aumento do controle das fronteiras; como também a força do euro frente ao dólar.

${ }^{7}$ O MRE destaca que o único país onde "quase" toda a comunidade brasileira está regularizada e computada em estatíticas oficiais é no Japão.

8 "O Espaço Schengen é uma área criada por convenção entre países europeus na qual não há controles fronteiriços ou alfandegários. Nesse espaço, cidadãos brasileiros podem ingressar sem necessidade de visto e, caso desejem circular entre os países do Acordo de Schengen, não precisam apresentar seus passaportes nas fronteiras. No entanto, alguns requisitos podem ser necessários para ingresso no espaço europeu". Informações dispomiveis na página web do MRE. http://www.portalconsular.itamaraty. gov.br/cartilhas/alerta-migratorio-espaco-schengen 
Juntamente com os elementos apontados acima, o forte vínculo histórico e a estreita relação diplomática entre Portugal e o Brasil têm feito de Portugal o principal destino de brasileiros, revezando essa preferência com o Reino Unido. Segundo Feldman-Bianco (1996, apud CAVALCANTI, PARELLA e SOLÉ, 2011), Portugal tem sido escolhido como primeiro destino, tanto pela facilidade linguística quanto pelos acordos profissionais entre os países, mas também como forma de mobilidade e novas oportunidades na União Europeia. Os autores destacam ainda que dentro desse grupo de imigrantes podem ser identificados muitos brasileiros e brasileiras qualificados, e o fato de Portugal estar inserido na União Europeia tem motivado muitos profissionais a escolher esse país como porta de entrada para outros países da Europa. Vale ressaltar que a Europa não era vista somente como um destino econômico, mas também como forma de aumentar o próprio capital social e simbólico, pois o continente "era considerado por muitos brasileiros como mais igualitário, mais culto, mais elegante, mais seguro e menos corrupto que o Brasil" (MARGOLIS, 2013, p.135)

\section{Imigração brasileira na Espanha: pequena em números, mas grande em representatividade?}

Segundo Margolis (2013), os brasileiros começaram a chegar à Espanha por volta dos anos de 1997 e essa população continuou a crescer por toda a década de 2000. Segundo Cavalcanti, Parella e Solé (2011), a consolidação da Espanha como país de imigração brasileira se deu devido às dificuldades da migração para países tradicionais, como Estados Unidos e Reino Unido, à desvalorização do dólar em relação à moeda brasileira, ao fortalecimento do Euro e o controle das fronteiras aeroportuárias de Reino Unido. Para Cavalcanti, Parella e Solé, 
Brasil es tanto emisor como receptor de población migrante. Siguen existiendo las profundas desigualdades sociales en cuanto a niveles de ingresos, oportunidades de acceso a la educación, acceso a los servicios sanitarios y hábitat. Persisten la exclusión social, la injusticia social y el racismo en una economía situada entre las 10 economías más potentes del mundo. Brasil es un país dividido y de fuertes contrastes. Las expectativas de una vida mejor, la falta de oportunidades para acceder a los recursos o para lograr la movilidad ocupacional y social ascendente, mueven a muchos brasileños a emigrar (2011, p. 18).

$\mathrm{Na}$ Espanha, a imigração brasileira está presente por todo o território espanhol, e tem sua maior concentração na Comunidade Autônoma da Catalunha, representando 22\% desta população, seguido pela Comunidade de Madri, com 17\%, Andalucía, Galicia, 10\% e Comunidade Valenciana com 9\%. Cavalcanti, Parella e Solé, (2011, p.58) destacam que "la mayor presencia relativa de brasileños en Castilla-La Mancha y sobre todo en Galicia, atribuible a su proximidad con Portugal - país que cuenta con una importante comunidad brasileña"; essas duas localidades juntas representam $11 \%$ da imigração brasileira, tornando-as com forte representatividade en tal contexto. Cavalcanti, Parella e Solé, (2011, p. 99) ressaltam ainda que a proximidade entre Espanha e Portugal, a semelhança linguística, "la libre circulación entre ambos países y sus diferencias salariales, motivan el flujo de brasileños y brasileñas de Portugal hacia España" e que, segundo relatos de brasileiros, Portugal é um país que se realiza o "rito de paso".

A população da Espanha hoje é de 46.572.132, segundo os últimos dados do Instituto Nacional de Estadística/INE de Espanha. Os imigrantes no país correspondem a aproximadamente $11.2 \%$ de sua população total, e o coletivo de nacionalidade brasileira corresponde a 
1,2\% desse número. Mesmo que o número de brasileiras(os) na Espanha seja considerável (58.277 imigrantes) ${ }^{9}$, se fizer a comparação com outros coletivos estrangeiros, os brasileiros têm pouca representatividade numérica, e não faz parte dos quinze maiores coletivos estrangeiros no Estado espanhol. Por exemplo, a România é o país com o maior coletivo imigrante na Espanha, representando $19,7 \%$ da população imigrante, são 1.043.516 romenos no país. Entre os 15 maiores coletivos estrangeiros na Espanha, dos países da América do Sul, têm o Equador (158.673), ocupando a oitava posição dos coletivos, seguido pela Colômbia (124.531) em décima primeira e Bolívia (93.122) em décima terceira posição, representando respectivamente $4 \%$ e $3 \%$ entre esses coletivos.

O número de imigrantes de nacionalidades originários da América do Sul é de 554.496. Se compararmos o número de imigrantes brasileiros com os outros coletivos de países da América do Sul, o Brasil tem uma população semelhante às do Peru (61.456) e Argentina (60.406), e ocupa a sexta posição entre os maiores coletivos dessa região. Gostaria de ressaltar e recorda-los que mesmo que o coletivo brasileiro represente uma pequena parcela da população imigrante na Espanha, vale destacar que muito brasileiros vivem na Espanha como cidadãos europeus devido à dupla cidadania que possuem ${ }^{10}$.

\footnotetext{
${ }^{9}$ Chamamos a atenção referente a dois dados: primeiro é que o MRE do Brasil informa que há aproximadamente 86.691 de brasileiros na Espanha, e o Ministério espanhol apresenta o número de 58.277 brasileiros no país, uma diferença entre um dado e o outro é de 28.414 pessoas. Vale recordar que o Brasil trabalha com estimativas e para chegar a esses números são conjugadas várias informações, considerando as saídas do país com passaporte brasileiros e também o relato de que há familiares vivendo em outros países. E os datos espanhois são referentes a imigrantes brasilerios com cartão de residencia. Isso demonstra que o número de brasileiros na Espanha é muito maior que os apresentados pelo governo local, deixamos claro que o artigo apresenta dados oficiais disponibilizados pelo estado Espanhol.

${ }^{10}$ Cito como exemplo minha própria experiência na Espanha, minha família é composta com quatro pessoas (eu, meu marido e dois filhos) somente eu tenho passaporte brasileiro, os outros três possuem passaporte italiano, trago esse exemplo para ilustrar como os números referentes aos brasileiros, sobretudo na Europa, podem ser muito
} 


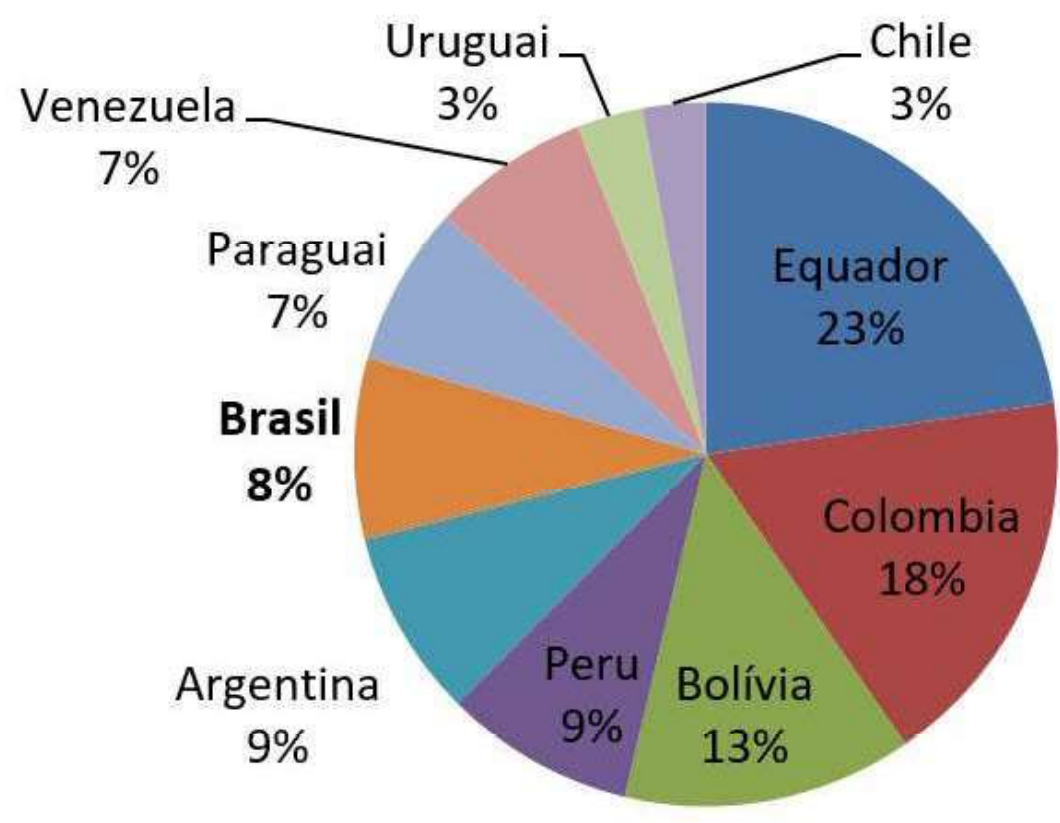

Fonte: elaboração própria a partir dos dados disponibilizados pelo INE. Gráfico 1 - Porcentagem correspondentes às nacionalidades da América do Sul

Segundo Margolis (2013), mesmo que seja considerável o número de brasileiros na Espanha, "quando a mídia e os investigadores espanhóis focalizaram a atenção nos imigrantes, os brasileiros não foram sequer mencionados", destaca ainda que do ponto de vista dos espanhóis os imigrantes eram os equatorianos, marroquinos e outros e os brasileiros não eram imigrantes e sim jogadores de "futebol, artistas e estudantes".

Parece que os brasileiros na diáspora transitam como um coletivo imerso na invisibilidade; mesmo que alguns brasileiros prefiram viver de forma que não sejam percebidos, outros buscam destacar suas diferenças frente a outros imigrantes originários da América do Sul. Nos E.U.A, onde está concentrado o maior coletivo de brasileiros, as brasileiras e brasileiros utilizam-se de estratégias para não serem confundidos com os latinos americanos, "a fim de se distanciar de estereótipos negativos, o brasileiro salienta sua própria etnicidade distinta ao se distinguir do 
hispânico em termos de sua ética de trabalho, aparência física, classe social, educação, língua e cultura." (MARGOLIS, 2008, p.291).

Ao contrário dos E.U.A e Espanha, em Portugal os brasileiros não são invisíveis, tampouco confundidos com outros imigrantes, e suas identidades ficam evidentes ao "abrirem a boca", em que o sotaque e o vocabulário são os marcadores de diferenciação entre brasileiros e portugueses, como também entre brasileiros e outros imigrantes da América do Sul (PADILLA; SELISTER; FERNANDES, 2010). Margolis $(2013,2008)$ destaca ainda que a brasilidade é acionada a depender da situação, e que ser brasileiro nos E.U.U, na Europa ou no Japão é diferente de ser brasileiro no Brasil. Na realidade, o brasileiro só sabe o que é ser brasileiro e o que isso significa, quando saem do Brasil.

Assim como os marcadores de diferença são ressaltados no espaço migratório, os estereótipos construídos dos brasileiros em geral, sobretudo das brasileiras neste contexto, tomam proporções que muitas vezes os fazem vítimas dos próprios compatriotas, que os julgam da mesma forma que os locais (PADILLA, 2007). A autora destaca ainda que, mesmo que seja certo que há prostitutas brasileiras em Portugal, a maioria das imigrantes brasileiras não são prostitutas e em sua grande maioria se encontram em empregos na área de "restauração, hotelaria, lojas e setores domésticos", parece que mesmo com essas constatações, as informações muitas vezes se perdem no meio de uma visão enraizada de preconceitos sobre os imigrantes. Todavia "a fama de prostitutas" não se encontra somente em Portugal, mas também em outros países da Europa, como Itália (BASSANESI; BÓGUS, 2000) y Espanha (CAVALCANTI; PARELLA; SOLÉ, 2011 e PISCITELLI, 2009). Em um dos relatos da investigação, uma brasileira de aproximadamente 50 anos, casada com um suíço, residente na Suíça desde 1982, disse que depois de muitas tentativas de envolvimento com uma associação de latinos no país, 
percebeu que não era o que queria,

Então entre 1996/1997 junto com outras mães brasileiras resolveram fazer atividades para seu filhos, na tentativa de mudar o estereótipo da mulher brasileira, pois não éramos prostitutas, não éramos da noite; e gostaríamos de mostrar que nem todas as mulheres brasileiras eram assim, e o Brasil não se resumia em carnaval e samba, necessitávamos melhorar a autoestima e perceber a importância que temos em aprender mais uma língua, conscientizar que seria bom, importante (Entrevista realizada em Munique, outubro de 2015).

Esse relato ilustra como as brasileiras buscam estratégias para mostrar que não são "todas prostitutas", não são "todas iguais", como também reforça a ideia de que a aprendizagem da língua local é importante para a inclusão na sociedade de acolhida. Esse incômodo ou preocupação das brasileiras em relação aos estereótipos sobre as brasileiras é relatada com certa frequência entre as brasileiras imigradas e vale ressaltar que a imigração de brasileiras na Europa é muito grande e na Espanha, particularmente, representam $67 \%$ do coletivo brasileiro.

A brasileira apontada acima faz parte do primeiro movimento de brasileiros para o exterior nos anos 1980, una imigração caracterizada por ser masculina. Segundo Margolis (2013), entre os brasileiros imigrados nos anos 80, os homens representavam 70\% dessa população nos Estados Unidos e de maneira semelhante no Japão, e que, por volta dos anos 1990, os imigrantes, em relação ao gênero, começaram a se equilibrar, tanto nos E.U.A quanto no Japão. A autora aponta ainda que por volta dos anos 2000, segundo dados do Consulado do Brasil em Nova Iorque, o número de mulheres começou a ultrapassar o de homens.

Cavalcanti, Parella e Solé (2011) destacam que a elevada feminização da imigração brasileira na Espanha é uma das características 
que define esta migração e apontam que no ano de 2001 a porcentagem de mulheres registradas no país era de aproximadamente 70\% dos imigrantes brasileiros. Ainda que o número de homens tenha crescido ao longo dos anos do movimento migratório e o número de mulheres tenha passado por alterações, as mulheres brasileiras na Espanha sempre se apresentaram como maioria frente aos homens, mesmo que Cavalcanti, Parella e Solé destaquem que:

Pese a la marcada feminización del colectivo brasileño, se da una tendencia a la masculinización a lo largo de los años o, lo que es lo mismo, que el número de varones brasileños empadronados en España crece más rápidamente que el de las mujeres (2011, p.62).

O coletivo de mulheres brasileiras sempre foi muito maior que o dos homens e a imigração brasileira na Espanha têm como marca essa feminização, um fator que deve ser fortemente considerado ao se tratar dos estudos migratórios, principalmente para entendermos as lógicas, interesses e dinâmicas desses processos, já que os primeiros movimentos migratórios de brasileiros e brasileiras são caracterizados por serem um movimento masculinizado. Cavalcanti, Parella e Solé (2011) ainda destacam que "la tendencia a medio plazo es a la paridad entre sexos", o que parece que não é o que vem acontecendo no caso da Espanha, como podemos observar no gráfico abaixo. 


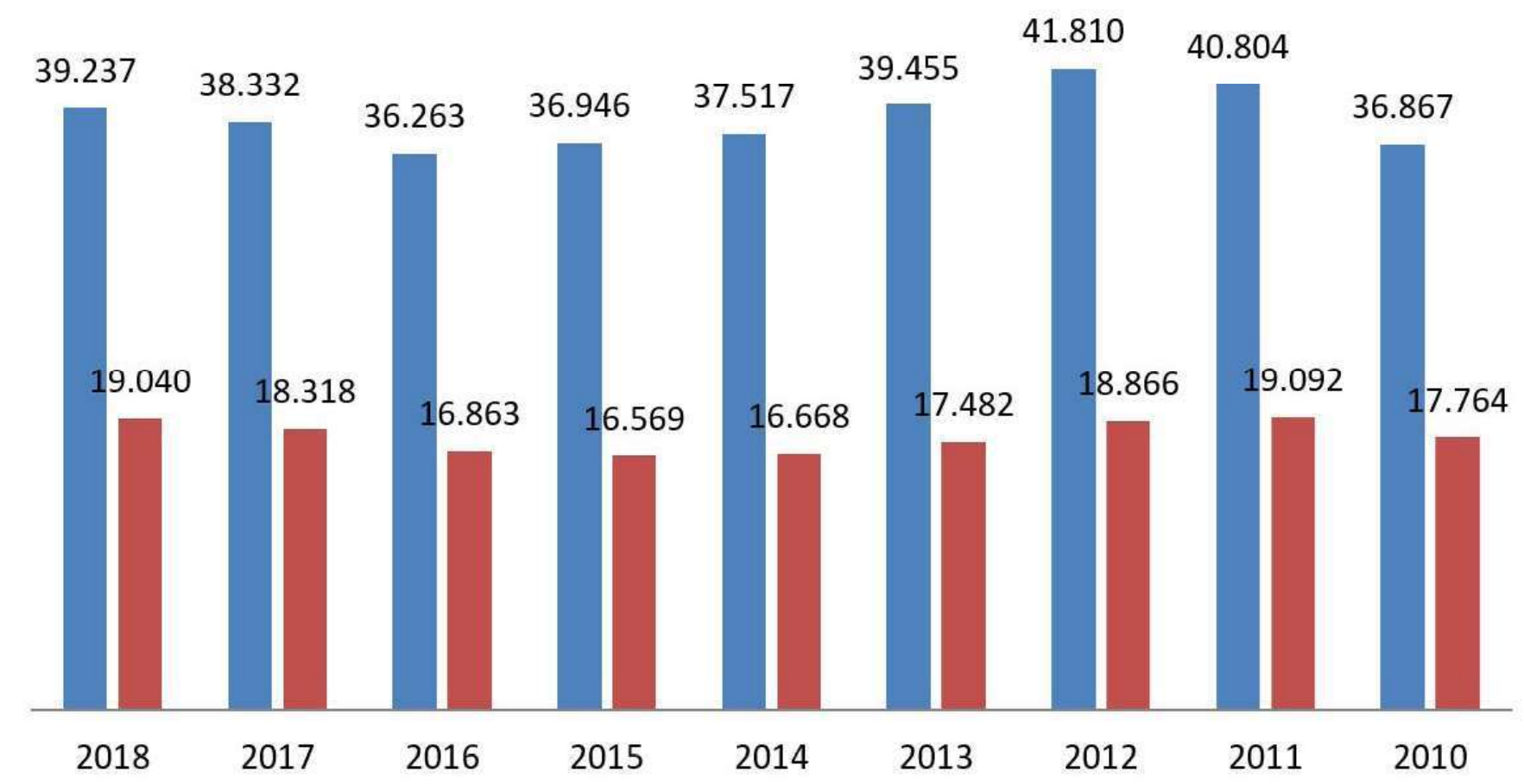

Fonte: Elaboração própria com base nos dados disponíveis no Portal de Inmigración del Gobierno de España ${ }^{11}$

\section{Gráfico 2 - Brasileiras e Brasileiros na Espanha}

Os dados de 2018 são referentes ao primeiro semestre do respectivo ano e que os outros números são às datas de 31 dezembro dos respectivos anos. Vale ressaltar que de dezembro de 2017 até os últimos dados referentes a 30 de junho de 2018, estes apresentam que a quantidade de imigrantes brasileiros na Espanha teve um aumento 1.627 pessoas em um semestre, deste número 905 mulheres e 722 são homens, representando um aumento de aproximadamente 3\% desses imigrantes. Os números referentes aos brasileiros com cartão de residência válido são de 58.277 brasileiros (as) no país, sendo 39.237 mulheres e 19.040 homens, portanto as mulheres representam 67,33\% da imigração brasileira na Espanha. A faixa etária predominante das (os) imigrantes brasileiras (os) na Espanha corresponde ao grupo ${ }^{12}$ de 16 e 64 anos, correspondendo a 93\% do total 11 Os dados disponíveis em: http://extranjeros.mitramiss.gob.es/es/Estadisticas/ operaciones/con-certificado/201806/Residentes_Tablas_PR_30-06-2018.pdf ${ }^{12} \mathrm{O}$ INE divide em três grupos etários: 0-15 anos; de 16-64 anos e 65 anos ou mais. 
desse coletivo (54.430), e a idade média desses imigrantes corresponde a 37,5 anos.

Ao comparar a idade média dos imigrantes brasileiros e brasileiras na Espanha com os maiores coletivos estrangeiros destacados anteriormente, é possível perceber que se seguem os mesmos perfis, relativos a esses dados, sendo o grupo etário entre 16 a 64 anos o maior grupo entre todos os coletivos imigrantes e quanto à idade média é de 38,2 anos, uma diferença de somente um ano. Vale destacar que há uma variabilidade etária entre os britânicos e os marroquinos, a idade média dos britânicos é de 53 anos e dos marroquinos é de 31,5 anos. Outra observação importante é que entre os maiores coletivos estrangeiros, a maioria dos imigrantes são mulheres, por exemplo: Alemanha com $51,9 \%$, Bolívia com 56,2\%, Colômbia com 54,1\% e Ucrânia com 56,7\%.

O Brasil se destaca por ter em seu coletivo imigrante na Espanha mais de $67 \%$ de mulheres; se consideramos que a porcentagem geral de mulheres imigrantes corresponde a $46,7 \%{ }^{13}$ dos imigrantes, o coletivo de mulheres brasileiras tem uma grande representatividade neste contexto. $\mathrm{Na}$ sequencia, será tratada a imigração brasileira na Catalunha com recorte desta imigração em Barcelona. A escolha desses recortes geográficos deve-se ao fato do trabalho de campo desta investigação tersido realizado na Associação de Pais de Brasileirinhos da Catalunha, que está localizada em Barcelona.

\section{Brasileiros na Catalunha}

A Espanha tem uma população de 46.572 .132 de habitantes distribuídos em dezessete comunidades e duas cidades (Ceuta y Melilla) ${ }^{13}$ Os dados mais gerais apontados foram retirados da publicação do Observatório Permanente de Inmigración. Disponível en: http://extranjeros.mitramiss.gob. es/es/Estadisticas/operaciones/con-certificado/201806/Residentes_Principales_ Resultados_30062018.pdf 
autônomas do país. Segundo os dados do Instituto Nacional de Estadística (INE) espanhol, a maior concentração de pessoas no país está localizada na comunidade autônoma de Andaluzia, são 8.379.820 habitantes; seguida pela Catalunha, com 7.555.830 e Madrid, com 6.507.184. Vale destacar que os maiores coletivos estrangeiros também estão localizados nas mesmas comunidades autônomas, e correspondem a $65,9 \%$ do total dos estrangeiros no país, segundo os dados do Observatório Permanente da Imigração da Espanha. Assim como as maiores concentrações da população de Espanha estão nas comunidades descritas, as maiores concentrações de imigrantes brasileiros no país também se encontram nas mesmas Comunidades.

A Comunidade Autônoma da Catalunha, comunidade onde se encontra o maior número de imigrantes brasileiros, também é a localidade onde se encontram três iniciativas que promovem o ensino da língua e cultura do Brasil para filhos de brasileiras e brasileiros: a Associação de Pais de Brasileirinhos da Catalunha (APBC), em Barcelona e a APBC/ Canet de Mar, locais onde foram realizados observação participante, e a Tribo Verde e Amarelo no município de Sant Joan Despí. As três iniciativas estão localizadas na província de Barcelona, em três municípios diferentes, e por este motivo o artigo apresenta este recorte geográfico.

A Comunidade Autônoma de Catalunha está situada ao noroeste do Estado espanhol, tem una extensão de $32.108,2 \mathrm{~km}^{2}$, limita ao leste com o mar Mediterrâneo, ao norte com França e Andorra, e ao oeste e ao sul com Aragão e Comunidade Valenciana. Atualmente, a Catalunha conta com mais de 7 milhões e 500 mil habitantes, distribuídos em 946 municípios. Tem a divisão administrativa em quatro províncias: Barcelona, Girona, Lérida e Tarragona, sendo a cidade de Barcelona a capital da Comunidade Autônoma e da província.

A população estrangeira na Catalunha corresponde a aproximadamente $13,80 \%$ do total dos habitantes, uma população 
consideravelmente expressiva. Os imigrantes marroquinos representam o maior coletivo estrangeiro na Catalunha, ao comparar o número de imigrantes marroquinos com o número de imigrantes do coletivo brasileiro, observamos que o número de imigrantes marroquinos é de aproximadamente doze vezes maior que o número de brasileiras e brasileiros na Comunidade. As brasileiras e brasileiros na Catalunha representam $1,7 \%$ da população imigrante, e estão entre os vinte maiores coletivos imigrantes na Comunidade, como podemos observar na Tabela 1 a seguir.

Tabela 1 - População estrangeira na Catalunha (2017, total de 1.041.362)

\begin{tabular}{l|l|l} 
País de Origem & $\begin{array}{l}\text { Total da população } \\
\text { do país }\end{array}$ & $\begin{array}{l}\text { \% referente al total da } \\
\text { população estrangeira }\end{array}$ \\
\hline Marrocos & 207.082 & $19,89 \%$ \\
\hline Rumanía & 89.071 & $8,55 \%$ \\
\hline China & 57.239 & $5,50 \%$ \\
\hline Itália & 51.761 & $4,97 \%$ \\
\hline Paquistão & 44.202 & $4,24 \%$ \\
\hline França & 32.236 & $3,10 \%$ \\
\hline Bolívia & 30.655 & $2,94 \%$ \\
\hline Honduras & 27.907 & $2,68 \%$ \\
\hline Equador & 26.696 & $2,56 \%$ \\
\hline Colômbia & 26.406 & $2,54 \%$ \\
\hline Russia & 23.599 & $2,27 \%$ \\
\hline India & 21.430 & $2,06 \%$ \\
\hline Ucrânia & 21.317 & $2,05 \%$ \\
\hline Senegal & 20.323 & $1,95 \%$ \\
\hline Reino Unido & 18.832 & $1,81 \%$ \\
\hline Peru & 18.286 & $1,76 \%$ \\
\hline Argentina & 18.179 & $1,75 \%$ \\
\hline República Dominicana & 18.074 & $1,74 \%$ \\
\hline Alemanha & 17.893 & $1,72 \%$ \\
\hline Brasil & 17.702 & $1,70 \%$ \\
\hline Fonte: & & \\
\hline
\end{tabular}

Fonte: elaboração própria a partir dos dados disponíveis na página web do 
Idescat $^{14}$.

O número de brasileiras e brasileiras na Catalunha, comparados a outras nacionalidades de origem da América do Sul, passa a não ter muita diferença, pois a variação entre o maior coletivo (2,94\% da Bolívia) e do Brasil $(1,70 \%)$ é pequena $(1,24 \%)$. Mas se considerar somente os maiores coletivos da América do Sul, o coletivo de brasileiros representa aproximadamente $13 \%$ dos imigrantes procedentes desses países. Se somar o total de imigrantes dos seis maiores coletivos da América do Sul, e comparar com o total de imigrantes marroquinos (o maior coletivo), terá somente $66.6 \%$ desses números. Isso indica que as nacionalidades da América do Sul são relativamente pequenas no contexto imigratório Catalão, e que a população marroquina na Comunidade é muito expressiva, e é preciso somar todos os imigrantes da América do Sul para se ter um número mais expressivo nesse espaço.

\section{Tabela 2 - Maiores coletivos da América do Sul}

\begin{tabular}{l|l}
$\begin{array}{l}\text { Maiores coletivos } \\
\text { da América do Sul }\end{array}$ & $\begin{array}{l}\text { Número de imigrantes } \\
\text { na Cataluña (137.924) }\end{array}$ \\
\hline Bolivia & 30.655 \\
\hline Equador & 26.696 \\
\hline Colômbia & 26.406 \\
\hline Peru & 18.286 \\
\hline Argentina & 18.179 \\
\hline Brasil & 17.702 \\
\hline Paraguai & 13.000 \\
\hline Venezuela & 12.982 \\
\hline Chile & 9.344 \\
\hline Uruguai & 7.686
\end{tabular}

Fonte: Elaboração própria com base nos dados disponíveis no site do Idescat.

$\mathrm{Na}$ Catalunha, na Comunidade de Madri, em Andaluzia e ${ }^{14}$ Disponível em: http://www.idescat.cat/poblacioestrangera/?b=12\&lang=es 
Comunidade Valenciana residem $65,9 \%$ do total de estrangeiros. Madri e Barcelona são as províncias com maior número de residentes imigrantes, conjuntamente representando $30,9 \%$ do total. Na Catalunha os imigrantes, em sua grande maioria, estão localizados na província de Barcelona, onde se encontram $66,62 \%$ do total de estrangeiros, seguido por Girona (13,39\%), Tarragona (12,49\%) e Lleida (7,5\%).

As brasileiras e brasileiros estão distribuídos por toda a Comunidade Autônoma da Catalunha, sendo na província de Barcelona a localidade com o maior número de esses imigrantes são 8.689 brasileiras e brasileiros localizados nesta província; seguido pela província de Girona, onde se encontram 1.500 brasileiras (os); Tarragona com 1.449 brasileiras e brasileiros, e Lleida com 853 brasileiras e brasileiros. Podemos observar a porcentagem correspondente destes imigrantes por comunidade através do gráfico abaixo.

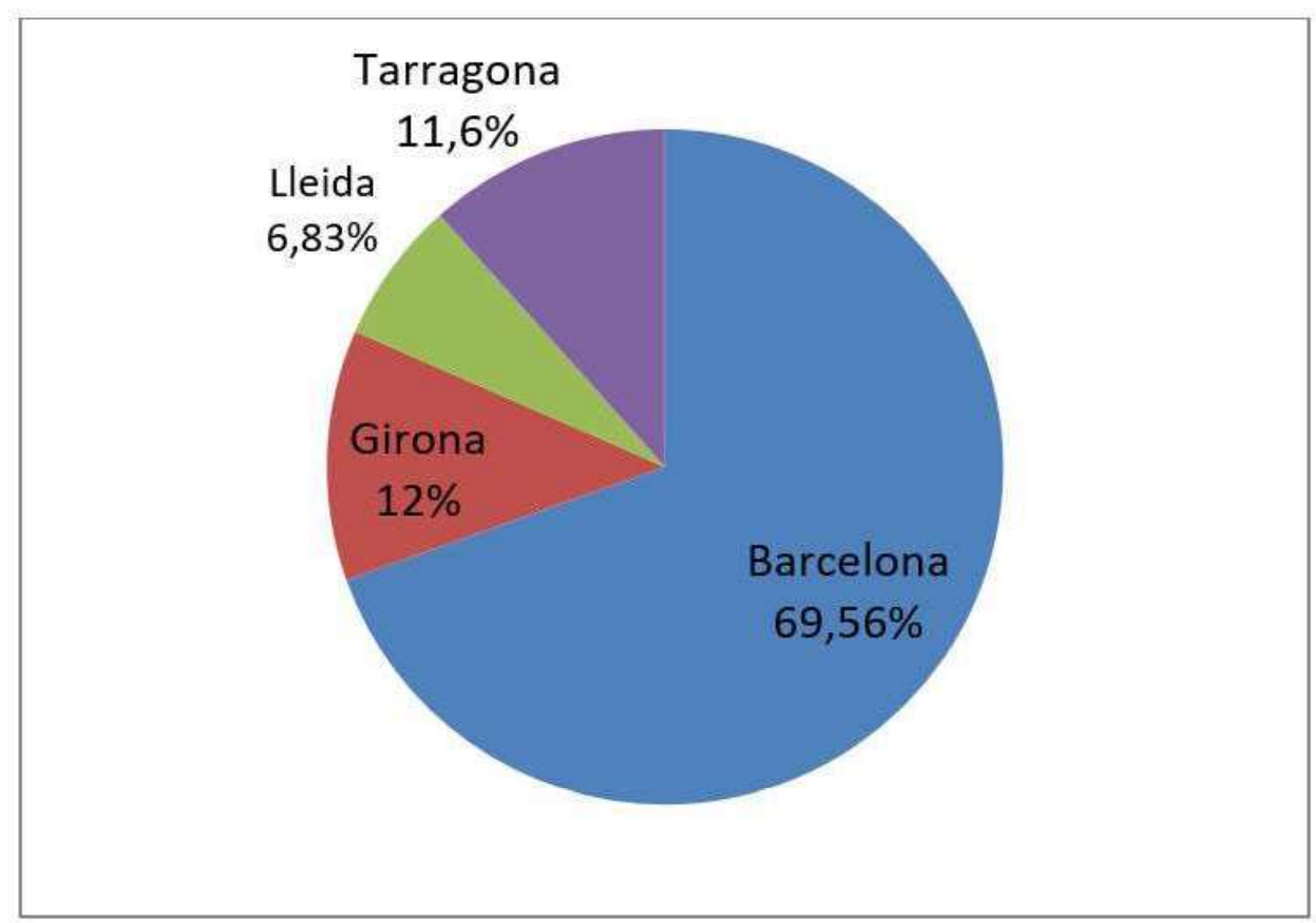

Fonte: elaboração própria a partir dos dados disponíveis no site do Idescat Gráfico 3 - Porcentagem de Brasileiros na Comunidade Autônoma da Catalunha 
Na sequência, serão apresentados os dados referentes à população estrangeira no município de Barcelona, apresentando a presença da comunidade brasileira, as suas características geográficas e populacionais; uma cidade de múltipla diversidade onde seus habitantes são oriundos de mais de 170 países diferente, sendo caracterizada como uma "ciudad cosmopolita, abierta, donde la cohesión social es una realidad"15, esses adjetivos estão ressaltados na página web da cidade, em que a qualidade de vida na cidade é evidenciada, parecendo um convite para quem queira viver ali e isso talvez justifique a quantidade de imigrantes em Barcelona.

\section{O Brasil em Barcelona: o verde e ama- relo en las calles}

A província de Barcelona é composta por 311 municípios $^{16}$, sendo Barcelona a capital da Catalunha e o maior município da província. Barcelona representa $24 \%$ do total da superfície de Catalunha e $74,4 \%$ do total da população catalã. Está situada na costa noroeste da Península Ibérica, aberta ao mar Mediterrâneo. Segundo o site $^{17}$ da cidade, Barcelona tem atraído gente de todas as partes do mundo, e isso faz da capital catalã "poliglota y especial. Son las personas que viven en ella, con origen y culturas diversas, las que han hecho una ciudad cosmopolita, diversa e intercultural". Além disso, Catalunha tem língua própria, o catalão, uma língua derivada do latim, como o castelhano e a língua portuguesa. $\mathrm{O}$ catalão e o castelhano são as línguas oficiais na Comunidade Autônoma,

\footnotetext{
${ }^{15}$ As informações foram recolhidas da página web do município de Barcelona. Para mais informações acessar http://meet.barcelona.cat/es/descubre-barcelona/barcelonaactual/calidad-de-vida

${ }^{16}$ Para mais informações sobre a província e seus municípios acessar https://www.diba. cat/es/web/ladiputacio/institucion

${ }^{17}$ Para mais informações acessar: http://meet.barcelona.cat/es/descubre-barcelona/laciudad-y-sus-origenes/identidad
} 
e isso faz da região uma comunidade bilíngue por natureza; como outras regiões da Espanha, a exemplo: a Comunidade Autônoma do País Vasco, com a língua basca e na Galícia com a língua galega.

Barcelona se destaca por ser um "núcleo empresarial, tecnológico e industrial, com um importante motor econômico", tornando-se uma das maiores áreas metropolitanas da Europa. É uma cidade onde se podem "oír y hablar todas las lenguas imaginables"; segundo Oliver (2016), em seu artigo publicado na revista Barcelona Metròpolis ${ }^{18}$, destaca que na Catalunha se "hablan más de trescientas lenguas. Barcelona, que aglutina gran parte de la inmigración que llega al territorio, se ha convertido en un mosaico muy diverso de culturas y lenguas" (OLIVER, 2016, p.86).

$\mathrm{Na}$ página web do município de Barcelona ${ }^{19}$ é destacado que a composição da população estrangeira é composta por 174 nacionalidades diferentes, e isso faz de Barcelona uma cidade de forte diversidade. A população imigrante representa $17,58 \%$ dos habitantes, as brasileiras e brasileiros na cidade representam $0,39 \%$ do total de habitantes (estrangeiros e nacionais), e com base nos números de estrangeiros representam $2,22 \%$ desta população ${ }^{20}$.

Quando se observa os maiores coletivos estrangeiros em Barcelona, nota-se que o coletivo brasileiro ocupa a $18^{\circ}$ posição entre as nacionalidades mais numerosas. A nacionalidade italiana ocupa a primeira posição. É importante destacar que assim como as brasileiras e brasileiros possuem dupla cidadania, inclusive italiana, os argentinos

${ }^{18}$ A Revista Barcelona Metròpolis é uma revista trimestral editada pelo Ayuntamiento de Barcelona desde o ano de 1986. Aborda temas culturais, urbanísticos e sociaias que, segundo a revista, são relevantes para la ciudade. Para mais informações acessar: https://www.barcelona.cat/metropolis/cat

19 Para mais informações acessar: http://ajuntament.barcelona.cat/premsa/wp-content/ uploads/2018/06/18_001_Poblaci\%C3\%B32018.pdf

${ }^{20}$ Os dados referentes aos números da população nacional e strangeira em Barcelona forame xtraídos do site: http://www.bcn.cat/estadistica/castella/dades/index.htm . Los datos son refentes a la fecha de enero de 2017. 
também possuem, e isso contribui com o número expressivo de italianos em Barcelona. A partir dos dados que se referem ao país de nascimento dos imigrantes, o total de brasileiras(os) que declararam que nasceram no Brasil é de 10.592, mas 4.253 apresentam outra nacionalidade (espanhola, italiana e portuguesa, por exemplo) no momento de fazer o registro municipal. Com relação aos argentinos os números são maiores, são mais de 22 mil que declararam ter nascidos na Argentina, mas somente 6.076 fizeram seu registro como argentinos.

Quando analisados os números referentes aos coletivos estrangeiros procedentes da América do Sul, percebe-se que o coletivo brasileiro em Barcelona passa a ocupar a sétima posição entre essas nacionalidades, e tem uma representatividade significativa entre esses grupos.

\section{Tabela 3 - Imigrantes Sul Americanos em Barcelona}

\begin{tabular}{l|l|l|l} 
Nacionalidade & Total & Homens & Mulheres \\
\hline Bolívia & 9.024 & 3.611 & 5.413 \\
\hline Colombia & 9.004 & 4.026 & 4.978 \\
\hline Perú & 8.316 & 3.789 & 4.527 \\
\hline Ecuador & 7.978 & 4.048 & 3.930 \\
\hline Brasil & 6.339 & 2.835 & $3.504(55,28 \%)$ \\
\hline Venezuela & 6.252 & 2.813 & 3.439 \\
\hline Argentina & 6.076 & 3.012 & 3.064 \\
\hline Paraguay & 3.968 & 1.154 & 2.814 \\
\hline Chile & 3.778 & 1.905 & 1.873 \\
\hline Uruguay & 1.461 & 735 & 726
\end{tabular}

Fonte: elaboração própria a partir dos dados disponíveis no site do Ayuntamiento de Barcelona

A partir das análises sobre os números referentes aos imigrantes de nacionalidade brasileira em Barcelona, é possível perceber que este 
coletivo parece relativamente pequeno em comparação aos maiores coletivos imigrantes, como é o caso dos imigrantes de nacionalidade italiana que são mais de 28 mil deles, três vezes mais que de o número de brasileiros. Vale recordar que o coletivo brasileiro na Catalunha representa somente $1,70 \%$ do total dos imigrantes, como demostrado na Tabela 8.

André (2007), em sua investigação sobre os adolescentes brasileiros em Barcelona, sugere que a presença de brasileiras e brasileiros em Barcelona parece ser maior do que realmente é, pelo fato de que muitos barceloneses e turistas circularem "pela cidade com suas camisetas verde e amarela, suas Havaianas"21, ou suas camisetas do Barça com o nome de Ronaldinho ${ }^{22}$ nas costas" (ANDRÉ, 2007, p.142-143), acrescenta-se ainda as brasileiras e os brasileiros que estão registrados em Barcelona com nacionalidade italiana e espanhola, contribuindo para a visibilidade deles pelas ruas.

André (2007) destaca também que o aumento de bares e restaurantes brasileiros em Barcelona, como as ofertas nas discotecas de noites brasileiras ou festas deste estilo são visíveis, e ressalta que "alguns locais de lazer conseguem oferecer um ambiente próximo ao estilo brasileiro e inclusive com a presença de muitos deles ali, ao contrário, outros somente utilizam a brasilidade para captar os clientes" (ANDRÉ, 2007, p. 143). De fato os elementos apontados corroboram para a visibilidade deste coletivo em Barcelona, ainda que os dados oficiais apontem que pareçam menos.

${ }^{21}$ Havaianas é uma marca de chinelos brasileiro muito popular que foi tomado no mercado internacional.

${ }^{22} \mathrm{Na}$ coluna Vivir do jornal La Vanguardia de 25 de maio de 2004, Ramón Suné escreveu um artigo intitulado "Brasilona: las razones de una simpatía mutua: lo brasileño está de moda en barcelona" em que destaca que "Romário, Ronaldo, Rivaldo y, sobre todo, Ronaldinho, han dejado huella en la ciudad con esos destellos de "futebol arte", e isso segue até hoje com novos jogadores brasileiros na equipe catalã do Barcelona (André, 2007). 
As imigrantes e os imigrantes brasileiros em Barcelona estão distribuídos pelos vários distritos do município. André (2007), em sua investigação realizada no ano de 2005, destaca que além de os brasileiros terem fenótipo diversificado e que não se concentram em somente em poucos bairros, isso também contribui para que as eles se tornem menos visíveis. A observação da autora permite pensar que as brasileiras e brasileiros, sobretudo em Barcelona, utilizam de sua "brasilidade" (a referencia as cores da bandeira verde e amarelo, por exemplo) conforme os convém, ora gostam ser percebidos, ora não. Assim ocorre com o uso do idioma, quando não querem ser reconhecidos como brasileiro não falam em "brasileiro", uma estratégia que foi possível perceber ao circular de ônibus em Barcelona, por exemplo. Vale destacar que na época da investigação de André (2007) em Barcelona, o número do coletivo brasileiro correspondia a 6.023 (3.406 mulheres e 2.6717 homens) e hoje corresponde a 6.339 , podemos perceber que a diferencia é pequena entre os dois períodos, mas apresenta um aumento de $5 \%$ entre os dois períodos.

Na tabela 4 abaixo, podemos observar como os imigrantes estão distribuídos nos distritos de Barcelona, nota-se que o distrito com o maior número de imigrantes é o L’Eixample seguido pelos distritos Ciutat Vella e Sant Martí, respectivamente; o distrito com menor presença de estrangeiros é Les Corts. Durante a pesquisa, a investigadora morou no bairro Les Corts, e destaca que ainda que às vezes encontrasse brasileiras e brasileiros pelo distrito, na escola onde seus filhos estudaram no bairro Les Corts, não havia outras crianças brasileiras além de seus filhos, mas ressalta que havia crianças de outras nacionalidades, como venezuelanos, colombianos, italianos e chineses, por exemplo. 


\section{Tabela 4 - Distribuição de brasileiros por distritos em Barcelona}

\begin{tabular}{l|l|l|l}
\multicolumn{1}{c|}{ Distrito } & $\begin{array}{l}\text { Total } \\
\text { habitantes }\end{array}$ & Total Imigrantes & $\begin{array}{l}\text { Porcentagem } \\
\text { equivalente }\end{array}$ \\
\hline Eixample & 266.416 & 53.393 & $18,7 \%$ \\
\hline Cuitat Vella & 101.387 & 45.357 & $15,9 \%$ \\
\hline Sant Martí & 235.513 & 38.597 & $13,5 \%$ \\
\hline SantsMonjuic & 181.910 & 35.507 & $12,5 \%$ \\
\hline Nou Barris & 166.579 & 26.272 & $9,2 \%$ \\
\hline Horta Guinardó & 168.751 & 21.015 & $7,4 \%$ \\
\hline Gràcia & 121.347 & 19.574 & $6,9 \%$ \\
\hline Sarriá - Sant Gervasi & 149.279 & 17.792 & $6,2 \%$ \\
\hline Sant Andreu & 147.594 & 17.604 & $6,2 \%$ \\
\hline Les Corts & 82.033 & 9.796 & $3,4 \%$
\end{tabular}

Fonte: elaboração própria a partir dos dados disponíveis no site d Ayuntamiento de Barcelona ${ }^{23}$.

Barcelona tem dez distritos, formados por 73 bairros. Na tabela 5, logo abaixo, pode-se observar como estão distribuídos numericamente os estrangeiros, conforme a nacionalidade apresentada, nos distritos de Barcelona, destacando os três maiores coletivos e apresentando a quantidade de brasileiras e brasileiros nesses distritos.

\footnotetext{
${ }^{23}$ Para mais informacçoes acessar: http://www.bcn.cat/estadistica/castella/dades/anuari/ cap02/C020105.htm
} 
Tabela 5 - Estrangeiros nos distritos de Barcelona (Dados de janeiro 2017)

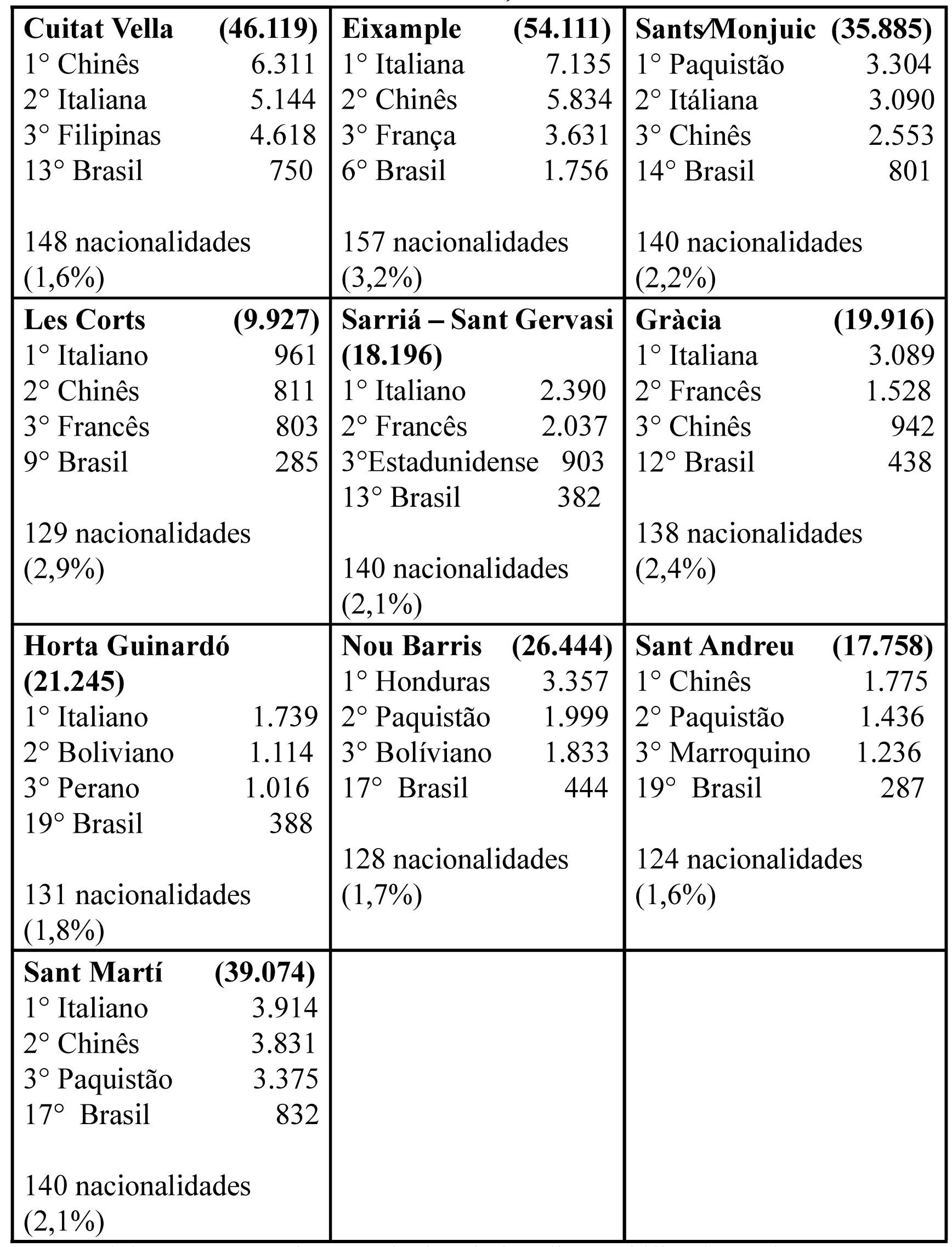

Fonte: elaboração própria a partir dos dados disponíbilizados pelo Departamento de Estadística do Ayuntamiento de Barcelona ${ }^{24}$

${ }^{24}$ Dados disponíveis em: site: http://www.bcn.cat/estadistica/castella/dades/inf/pobest/ 


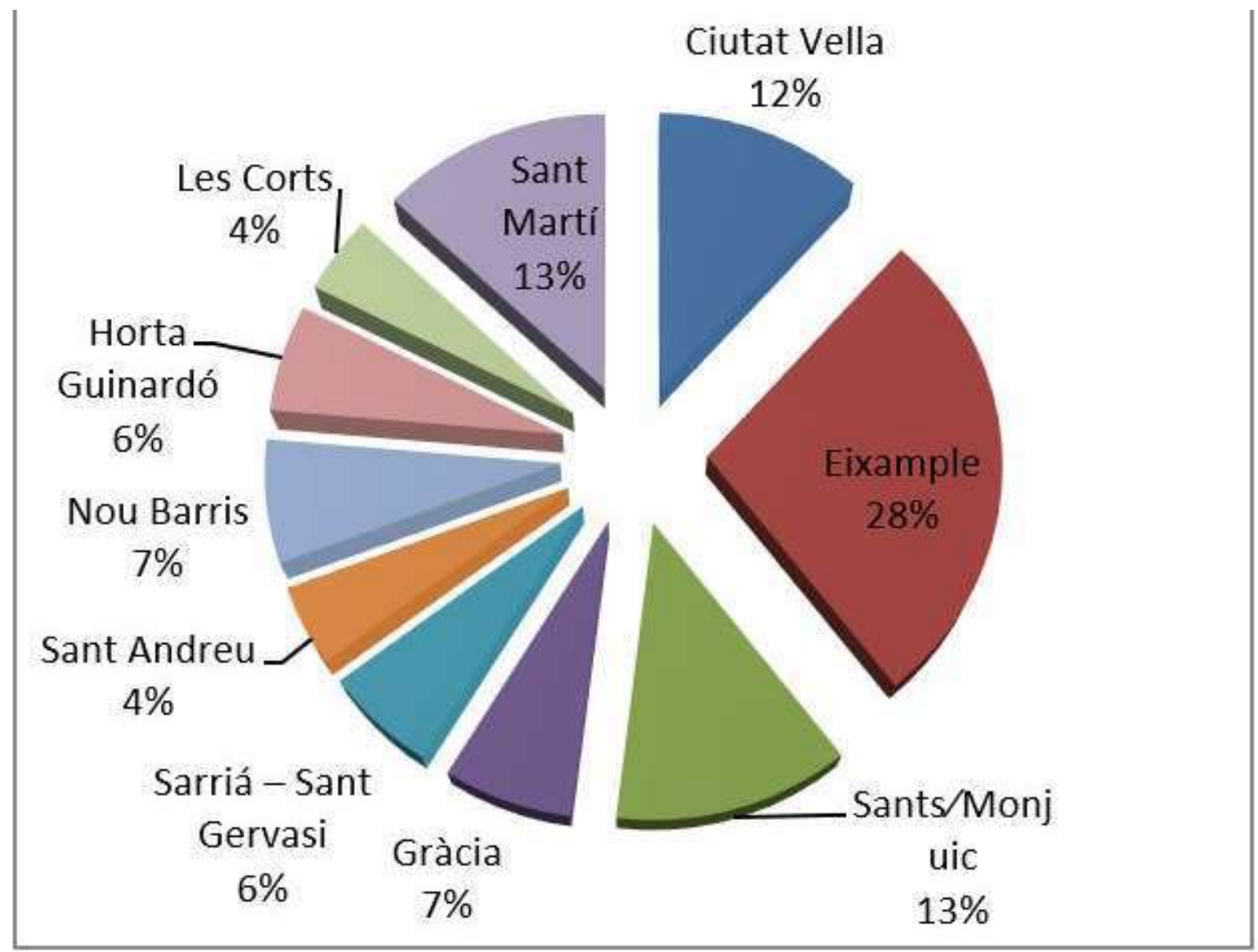

Fonte: elaboração própria a partir dos dados disponíbilizados pelo Departamento de Estadística do Ayuntamiento de Barcelona ${ }^{25}$

\section{Gráfico 4 - Distribuição de brasileiras (os) por distritos}

Pode-se observar que as brasileiras e os brasileiros estão distribuídos de forma proporcional nos distritos de Barcelona, tendo uma variação de $1,6 \%$ entre o maior $(3,2 \%$ e 1,6\%) o menor número. Nota-se também que o distrito com maior número deste coletivo está localizado em L'Eixample; e os distritos de Sant Andreu e Ciutat Vella são os com menos presença dessa imigração.

A partir dos dados recolhidos dos sócios da Associação de Pais de Brasileirinhos da Cataluña/APBC, onde foi realizada a pesquisa de doutoramento, 25\% deles vivem no distrito de Sant Martí, já os outros sócios estão distribuídos de forma proporcional nos outros distritos da

25 Dados disponíveis em http://www.bcn.cat/estadistica/castella/dades/inf/pobest/ pobest17/part1/index.htm 
cidade. No distrito de Sant Martí, a nacionalidade brasileira ocupa a $17^{\circ}$ posição, entre 140 nacionalidades registradas. O Distrito é composto por dez bairros, segundo informações da página web do município, os bairros partilham de um vínculo comum, "todos tienen un largo pasado industrial". Além dos Jogos Olímpicos de Barcelona transformarem a cidade, o distrito de Sant Martí teve suas especificidades "se abrió definitivamente al mar y cambió las fábricas, los almacenes y las naves industriales por viviendas nuevas, zonas verdes, equipamientos y complejos de empresas vinculadas a la sociedad de la información y la comunicación"26. O Distrito é caracterizado pela combinação de história e modernidade, onde se misturam atividades econômicas, formativa/ educativa e residenciais, portanto se convertendo em uma boa alternativa para se viver.

Destaca-se que no gráfico 5 estão inclusos três municípios que fazem parte da província de Barcelona, onde residem alguns dos sócios da APBC, são eles: Sant Feliu de Llobregat, Rubí e Canet de Mar; Sant Feliu de Llobregat está a $10 \mathrm{~km}$ de Barcelona, Rubí a $23 \mathrm{~km}$ y Canet de Mar a 47 km, destaco que em Canet de Mar há uma extensão da APBC, mas é em Barcelona que se concentra a maioria dos sócios, $80 \%$ deles.

\footnotetext{
26 Para mais informações acessar: https://ajuntament.barcelona.cat/santmarti/es/ conozca-el-distrito/historia/sant-marti-de-provencals-de-pueblo-distrito
} 


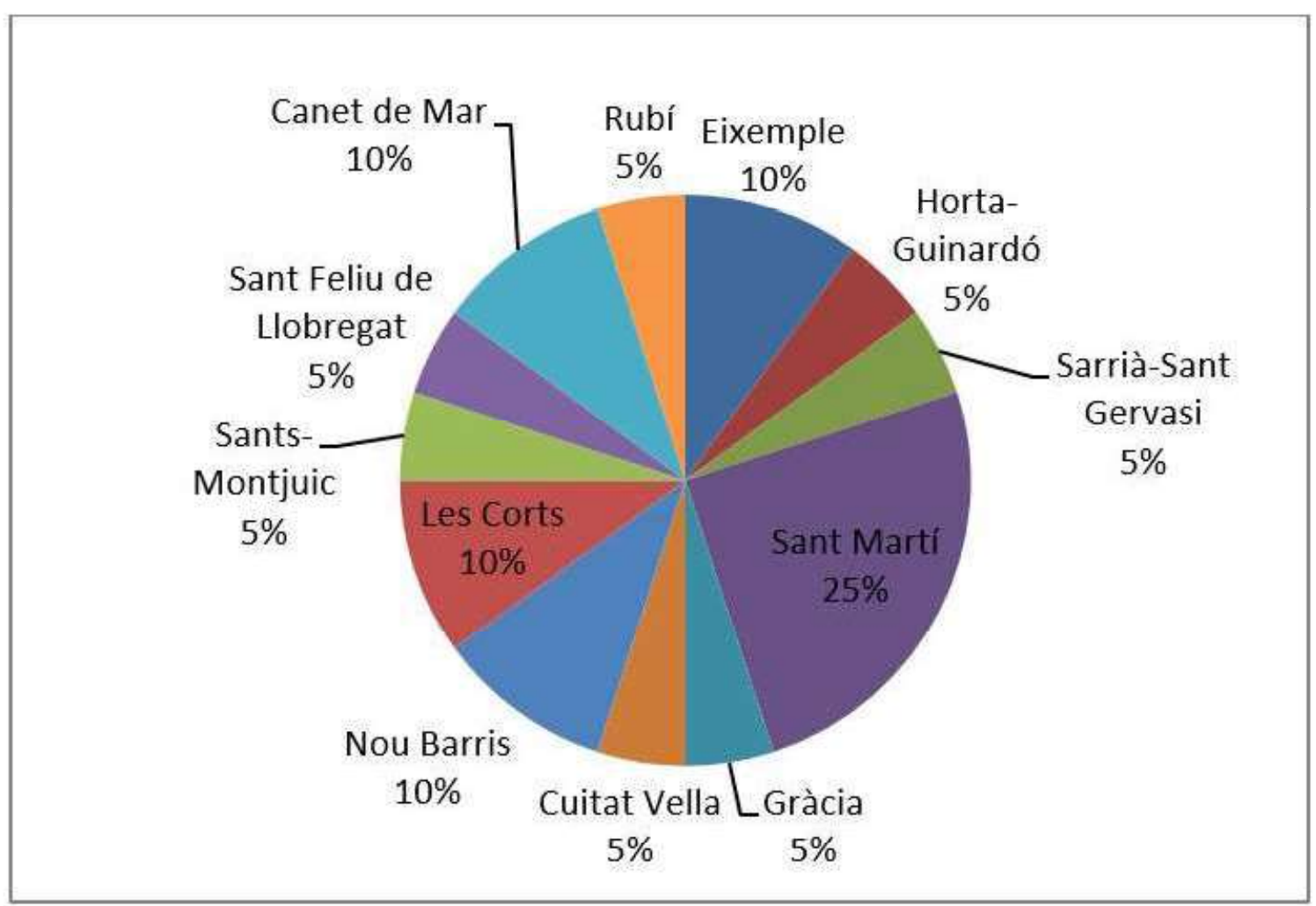

Fonte: elaboração própria a partir de dados de pesquisa pessoal

\section{Gráfico 5 - Localidade de morada sócios APBC}

No distrito de L'Eixemple, onde se encontram 28\% dos imigrantes de origem brasileira, entre os sócios da APBC 10\% deles vive neste distrito, uma porcentagem equivalente a outros distritos do município, como Les Corts e Nou Barris. Vale apontar que o distrito de L'Eixample é onde se encontra a maior quantidade de estrangeiros, e é o distrito com maior número de nacionalidades registradas (157), segundo informações na página web do Ayuntamiento de Barcelona, é o distrito onde estão os principais calçadões "principales paseos", "paseo de Gràcia, la rambla de Catalunya e paseo Sant Joan", e onde estão os edifícios mais emblemáticos, como a Sagrada Família, a rota do modernismo, Casa Battló e a Casa Milà (mais conhecida como La Pedrera). "Su interés turístico y comercial hace que hoy en día continúe siendo un eje central de la ciudad"27. Destaca-se que é em L'Eixample, ao lado da Casa Battló, que se encontra o Centro Cultural do Brasil em Barcelona (CCBB), um

\footnotetext{
${ }^{27}$ Parama mais informações acessar: https://ajuntament.barcelona.cat/eixample/es
} 
instrumento de execução da política cultural brasileira na Catalunha, um órgão subordinado ao Consulado Geral do Brasil em Barcelona e ao Ministério das Relações Exteriores do Brasil.

\section{Brasileiras e brasileiros no exterior e o Brasil: di- álogos entre MRE e as comunidades brasileiras}

Como já destacado anteriormente, há mais de 3 milhões de brasileiras e brasileiros vivendo no exterior e, segundo o MRE, para aumentar o dialogo entre Brasil e os brasileiros emigrados, o Ministério tem uma página web chamada "Brasileiros no Mundo", com o objetivo de "instrumentar e ampliar o diálogo entre o Ministério das Relações Exteriores e as comunidades brasileiras no exterior, e destas entre si". $\mathrm{Na}$ página web estão disponíveis informações sobre as comunidades brasileiras no exterior, trazendo, por exemplo, informações sobre as organizações brasileiras no exterior, ações do Governo de interesse dessas brasileiras e brasileiros no exterior, sobre as eleições para representantes de brasileiros no exterior e também sobre a "Conferência Brasileiros no Mundo"/CBM.

Segundo informações disponíveis na página web Brasileiros no Mundo, a conferência "Brasileiros no Mundo", uma ação do Governo do Brasil para pensar, conhecer e discutir a diáspora brasileira, tem como objetivo principal:

Permitir debate aberto e abrangente de assuntos sobre emigração brasileira e políticas públicas para brasileiros no exterior. Representantes dos Ministérios das Relações Exteriores, do Trabalho e Emprego, da Seguridade Social e da Educação, entre outros, apresentam trabalhos sobre ações em curso ou cogitadas nessa área. Acadêmicos reconhecidos 
A Conferencia está em sua sexta edição, a primeira ocorreu no ano de 2008, na cidade do Rio de Janeiro, reuniu representantes das principais comunidades de Estados Unidos, da América do Sul, de Europa Ocidental, do Japão, Austrália, África e Oriente Médio, com a "finalidade de debater os assuntos de interesse da diáspora brasileira”. Líderes comunitários e membros de associações no exterior foram estimulados a enviar contribuições para a Conferência, que tiveram a oportunidade de mandar informações sobre experiências e iniciativas como migrantes.

Segundo Moroni (2017), na primeira CBM foi discutida a importância de se criar uma rede de articulações entre os brasileiros, criando o Conselho de Representantes de Brasileiros no Exterior (CRBE), segundo a autora para estabelecer as bases do conselho, na II CBM, no ano seguinte, foram escolhidos membros para compor um Conselho provisório e se definiu o modelo para a seguinte eleição dos representantes nas comunidades. Os primeiros conselheiros eleitos por voto mundo afora tomaram posse na III CBM no ano de 2010. Moroni (2017) destaca que

O papel dos Conselheiros compreendia, entre outros aspectos, representar suas regiões nas CBMs, ocasiões em que foram realizados encontros com representantes do MRE e outros ministérios, e expor os problemas e desafios enfrentados pelas comunidades de brasileiros emigrados no mundo. Isso permitiu ao governo brasileiro conhecer melhor as especificidades e demandas de cada comunidade, ao mesmo tempo em que dava certa voz política a elas. A partir dessas informações, o governo começou a traçar algumas políticas públicas para os brasileiros

${ }^{28}$ Informações disponiveis na página web do Brasileiros no Mundo. Para mais informações acessar: http://www.brasileirosnomundo.itamaraty.gov.br/ 
emigrados. (MORONI, 2017, p.80).

As conferências são divididas por sessões temáticas; a primeira CBM aconteceu em dois dias e foi dividida da seguinte maneira: no primeiro dia: Sessão 1: Migrações, controles migratórios e emigração de brasileiros; Sessão 2: A situação dos brasileiros nas diferentes regiões do mundo; Sessão 3: Possibilidade e limites de ações governamental em benefícios dos brasileiros no exterior, e a última Sessão 4: Associações e redes de brasileiros no exterior, mídia e remessas. No segundo dia foram realizadas debates entre os representantes das comunidades brasileiras no exterior, em formato de mesas redondas e uma sessão plenária para debater as conclusões das sessões anteriores.

A partir da primeira conferência e seus debates, as conferências seguintes foram e são programadas segundo as demandas apresentadas em cada edição. A CBM teve seis edições, e a última aconteceu em maio de 2018 na cidade de Salvador/BA. Ressalta-se que é neste contexto de debates e apresentação de demandas de brasileiras e brasileiros emigrados que a Língua de Herança passa a compor as discussões, já tendo representantes sobre a temática na I e II edições da Conferência. Essas representantes além de representarem as comunidades brasileiras no exterior, também estão envolvidas com iniciativas que promovem o ensino da Língua de Herança do Brasil em suas comunidades, e isso significa que com discursos articulados conseguem mais visibilidade para, consequentemente, conquistarem suas demandas.

\section{Considerações Finais}

Este artigo buscou realizar uma breve análise sobre os aspectos gerais da diáspora brasileira, realizando um recorte geográfico e apresentando este coletivo em contexto espanhol, sobretudo, na 
Comunidade Autônoma da Catalunha. Partindo de uma temática mais ampla, a formação de iniciativas que promovem o ensino da língua e cultura brasileira (Língua de Herança) para filhos de brasileiras e brasileiros no exterior, foi exposto alguns dados referentes a pesquisa de campo, como também informações e os dados mais recentes referentes a esta imigração na Europa e na Espanha, apresentando o perfil da comunidade brasileira no país, sobretudo na Catalunha e em Barcelona, onde se encontra a Associação de Pais de Brasileirinhos da Catalunha, local da investigação.

Caracterizada por uma imigração transnacional e também recente, percebe-se que desde os primeiros movimentos migratórios de brasileiras e brasileiros até hoje, as motivações ainda são marcadas pelo desejo de "melhor qualidade de vida". Na Espanha essa imigração é fortemente marcada pela feminização, representando mais de $67 \%$ dos imigrantes brasileiros no país, característica presente desde o início desse movimento. Apontado como um coletivo imerso na invisibilidade, com exceção de Portugal, as brasileiras e brasileiros usam de diferentes estratégias para viver a imigração; a "brasilidade" é acionada a depender da situação, e ser brasileiro no Brasil é diferente de ser brasileiro em qualquer outro lugar do mundo.

A Comunidade Autônoma da Catalunha é a região com o maior número de imigrantes, inclusos os de origem brasileira, uma região caracterizada pelo multiculturalismo e plurilinguismo. Embora o coletivo brasileiro seja numericamente pequeno, em comparação com outras nacionalidades, apresenta-se bem representativo, já que muitos deles vivem ali com cidadania europeia. Em Barcelona, o coletivo brasileiro está espalhado por todo o município, tendo sua maior concentração no Distrito de L'Eixample. Para Cavalcanti (2004), o coletivo brasileiro por se apresentar disperso pela cidade de Barcelona, "tem a impressão de 
que são mais tolerados frente a outros coletivos", pois, segundo o autor, facilmente podem se passar por "africanos, árabes, asiáticos, europeus etc.", devido à "profunda mestiçagem" que existe entre as brasileiras e brasileiros. E, em virtude disso, permite uma "relativa invisibilidade, que consiste em ser visto porque se visualiza, mas não pode ser reconhecido aparentemente como imigrante brasileiro" (CAVALCANTI, 2004, p.20).

É considerando o grande fluxo da migração internacional brasileira, com mais de 3 milhões deles na diáspora, que o governo do Brasil passa a ouvir as comunidades localizadas em diferentes países, um momento que dão vozes aos representantes destas comunidades, em que apresentam suas demandas, suas dificuldades e preocupações no contexto de imigração, e é a partir deste cenário que ações voltadas às políticas de promoção da língua brasileira passam a tomar um novo significado, e inserem na pauta das discussões uma nova temática, o Português como Língua de Herança, o ensino da língua e cultura brasileira para "brasileirinhos" no estrangeiro, um movimento protagonizados por mulheres/mães brasileiras, que a partir de seus engajamentos em torno do ensino e manutenção da língua e cultura do Brasil, vêm buscando reconhecimento, legitimidade e visibilidade nos países de acolhimento, como também pelo governo brasileiro. A partir desta constatação é importante contestar a costumeira invisibilidade da mulher/mãe brasileira nos estudos sobre imigração e a necessidade de se compreender e analisar a presença e as formas de atuação, de afirmação e de representação das mulheres no contexto imigratório, como sugerem Assis (2007) e Padilha (2013).

Referências Bibliográficas

ALMEIDA FILHO, José Carlos Paes. Português Lingua de Herança. (2010) Entrevista disponível em: http://www.sala.org.br/index. 
php?option $=$ com_content\&view $=$ article $\&$ id $=270$ :portugues-lingua-deheranca\&catid=1116:outras-salas. Acesso em: 15/01/2015

ANDRE. Bianka P. De la integración deseada a la integración vivida: la experiencia de adolecentes brasileños en escuelas de Barcelona. (2007) Tese doutorado, Departamento de Didática e Organização Educativa de Ciências da Educação, Universidade de Barcelona/UB, Barcelona, Espanha

ASSIS, Glaucia. Mulheres migrantes no passado e no presente: gênero, redes sociais e migração internacional. Estudos Feministas, Florianópolis, 15(3): 336, setembro-dezembro, 2007. Acesso em: 03/11/2015

BASSANESI, M. \& BÓGUS, L. Brasilerios na Italia: movimentos migratórios e inserção social. 2000. Disponivel em: https://www.anpocs. com/index.php/encontros/papers/22-encontro-anual-da-anpocs/gt-20/ gt09-11/5103-bassanezi-bogus-brasileiros/file. Acesso em 25/09/2018

CAVALCANTI, L. Lembrança de emigração e realidade de imigração: o fenômeno migratório na Espanha e a recente chegada dos brasileiros. Cadernos CERU, N. 15 págs. 185-201, 2004. Disponível em: http://www. revistas.usp.br/ceru/article/view/75331/78872 Acesso em 20/10/2017

FUSCO, Wilson. Capital Social e Dinâmica Migratória: Um estudo sobre os brasileiros nos Estados Unidos. Campinas: Núcleo de Estudos de População/Unicamp. 83 págs, 2007. Disponível en: http://www.nepo. unicamp.br/textos/publicacoes/textos_nepo/textos_nepo_52.pdf. Acesso em $16 / 11 / 2015$

MACHADO, Igor. Brasileiros no exterior e cidadania (1980-2005). Revista TOMO, n. 26: JanJun, págs. 211-245, 2015. Disponível em: https://seer.ufs.br/index.php/tomo/article/view/4407/3645 Acesso em: 29/10/2015

MARGOLIS, M. Goodbye, Brazil: emigrantes brasileiros no mundo. São Paulo: Contexto, 2013

. Brasilerios no extrangeiro: a etnicidade, a auto-identidade e o outro. Revista de Antropologia, São Paulo, USP, V. 51 N ${ }^{\circ}$ 1, 2008. Disponível em http://www.revistas.usp.br/ra/article/view/27309 Acesso em: 29/10/2015 
MORONI, Andréia S. Português como língua de herança na Catalunha: representações sobre identificação, proficiência e afetividade. 2017. Tese de Doutorado/ Instituo de Estudos de Linguagem, Universidade Estadual de Campinas (UNICAMP). Campinas, SP

OLIVER, G. Un paisaje lingüístico diverso. Revista Barcelona Metrópolis Número 99, Março, pp. 86-87, 2016. Ajuntament de Barcelona. Disponível em https://www.barcelona.cat/metropolis/es/revistas Acesso em $05 / 03 / 2019$

PADILLA, Beatriz(2013). Gêneroe migracionesnuevas reconfiguraciones y protagonismos de mujeres latino-americanas. Anuário Americanista Europeu: Género y Migraciones, $\mathrm{n}^{\circ}$ 11, p. 1-9, 2013. Disponível em: http://www.red-redial.net/revista/anuario-americanista-europeo/article/ viewFile/252/246]. Acesso em 24/11/2015.

- A imigrante brasileira em Portugal: considerando o género na análise. In: MALHEIROS, J. A imigração brasileria em Portugal. Lisboa. ACIDI, 2007. Disponível em: https://www.om.acm.gov.pt/ documents/58428/179693/1_ImigrBrasileira.pdf/7d926056-f322-427a8393-73fb1848da37 Acesso em 11/04/2019

PADILLA, B.; SELISTER, M.; FERNANDES, G. Ser brasileira em Portugal: imigração, gênero e coloniedade. In: CARVALHO, Flavio et al (org). $1^{\circ}$ Seminário de Estudos sobre Imigração brasileira na Europa. Barcelona: Universitat de Bracelona, págs. 113-120, 2010. Disponivel em: https://seminariobrasileuropa2010.files.wordpress.com/2011/01/ livro-i-seminc3a1 rio-de-estudos-sobre-imigrac3a7c3a3o-brasileira-naeuropa.pdf Acesso em: 29/03/2019

PISCITELLI, A. Migración y sexualidad: de Brasil a Europa. Diálogo Latinoamericano sobre Sexualidad y Geopolítica - Observatorio de Sexualidad y Política - Rio de Janeiro, Agosto, 2009. Disponível em: http://docplayer.com.br/9311135-Migracion-y-sexualidad-de-brasil-aeuropa-adriana-piscitelli-brasil.html. Acesso em 29/04/2016.

SALES, Teresa. Brasileiros Longe de Casa. São Paulo: Cortez Editora, 1999

SOLÉ, C; CAVALCANTI, L. Y PARELLA, S. La inmigración brasileña 
en la estructura socioeconónica española. Documentos del Observatorio Permanente de la Inmigración(OPI). Ministerio de Trabajo e Inmigración: Madrid, 2011. Disponível em http:/extranjeros.mitramiss.gob.es/es/ ObservatorioPermanenteInmigracion/Publicaciones/fichas/archivos/Lainmigracion-brasilena-en-la-estructura-socioeconomica-de-Espana.pdf Acesso em 20/02/2017

.Nuevosretosdeltransnacionalismoenelestudiodelasmigraciones. Documentos del Observatorio Permanente de la Inmigración (OPI). Ministerio de Trabajo e Inmigración: Madrid, 2008. Disponível em http:// extranjeros.mitramiss.gob.es/es/ObservatorioPermanenteInmigracion/ Publicaciones/fichas/archivos/Nuevos_retos_del_transnacionalismo_ en_el_estudio_de_las_migraciones.pdf Acesso em 08/03/2019. 